\title{
Os jovens e a sexualidade: um panorama da realidade brasileira
}

Juventudes e sexualidade.

CASTRO, Mary Garcia; ABRAMOVAY, Miriam; SILVA, Lorena Bernadete da.

Brasília: UNESCO Brasil, 2004. 426 p.

O livro Juventudes e sexualidade é uma obra que vem preencher um espaço importante nos trabalhos sobre sexualidade e jovens. Visa divulgar estudos feitos pela UNESCO, que servirão de referência para muitas atividades, projetos e políticas públicas referentes à saúde sexual e reprodutiva. Abordando temas como a iniciação sexual dos jovens, a gravidez juvenil, contracepção, aborto, bem como violências, preconceitos e discriminações, o livro traz a visão e as opiniões dos jovens sobre essas questões. A pesquisa, realizada através de questionários $e$ grupos focais, envolvendo crianças, adolescentes e jovens de escolas em 13 capitais brasileiras e Distrito Federal, procurou contemplar todas as regiões do país. Buscou-se dar ênfase às representações e percepções dos diversos atores relacionados ao contexto escolar, além de uma caracterização sociodemográfica dos mesmos.

Sem descuidar dos conceitos e da historicidade do tema, as autoras iniciam a obra conceitualizando sexualidade, esclarecendo sobre a abrangência do tema e destacando, em seguida, as teorias referentes a esse campo, às relações de gênero e aos movimentos sociais por direitos humanos, sexuais e reprodutivos. De acordo com as pesquisadoras, tem ocorrido uma especial atenção às questões que envolvem sexualidade e juventude nas últimas décadas por parte da comunidade mundial, principalmente no que se refere a problemas relacionados à gravidez "precoce" e DST/ AIDS. Pontua-se também a questão de a juventude ser um ciclo decisivo para a demarcação de diferenças de gênero no campo de identidades. A partir disso, surge uma expressiva literatura voltada para 0 lugar da escola e da educação de jovens. Tratar de sexualidade em escolas envolve diversas questões e polêmicas, devido à complexidade do tema e às diferentes visões e crenças dos atores que compõem o contexto escolar. Em Juventudes e sexualidade, as autoras buscam discutir essa questão, chamando a atenção para a necessidade de projetos coerentes - ligados aos contextos desses jovens - que abram campos de discussão e reflexão e auxiliem na apropriação das questões referentes a esse assunto, através de um aprendizado efetivo.

Mas o que pensam esses jovens atualmente? Que idéias eles têm sobre aborto? Em que idade se iniciam sexualmente? E quanto a seus pais e professores? Que percepções possuem sobre esses temas? Essas questões e outras ajudam-nos a conhecer esses jovens e direcionar programas e políticas públicas, além de servir como importantes dados para conhecermos essa realidade e período de vida. Esse foi um dos objetivos da pesquisa que embasa esse livro. Importante colocar o cuidado que as autoras tiveram em não fazer generalizações, demostrando diferentes opiniões desses jovens, ressaltando peculiaridades de cada relato nos grupos focais, segundo gênero. $O$ estudo pode mostrar, dessa maneira, como esses jovens vivenciam suas sexualidades e sua afetividade.

Após explicar a metodologia e a caracterização sociométrica, em que se constata que a maioria dos alunos é do sexo feminino discutem-se os dados encontrados sobre o início da vida sexual e as interações afetivo-sexuais. Nesse estágio do livro discute-se o que esses jovens consideram ou não próprios de homens e mulheres, como eles se posicionam sobre a diversidade de parceiros, singularidades da vida amorosa e sexual, valores, virgindade, como se dão as conversas sobre sexo, entre outras questões. A pesquisa constata que a idade média da primeira relação sexual é mais baixa entre os alunos do sexo masculino. Observa-se uma tendência entre todos os pesquisados de relativizarem a virgindade, porém havendo ainda uma forte pressão para que a vida sexual dos rapazes inicie-se mais cedo. Um dado interessante, entre diversos outros coletados, é o fato de $70 \%$ dos jovens indicarem que só tiveram 
relações sexuais com um parceiro, o que questiona a corrente idéia de 'promiscuidade' sexual entre os jovens.

No terceiro capítulo, o tema discutido é gravidez juvenil. As autoras optam por utilizar esse termo, em vez de gravidez na adolescência, por o considerarem mais amplo, compreendendo adolescentes e jovens (de 10 a 24 anos). A intenção principal das autoras foi visualizar as percepções sociais contemporâneas sobre gravidez juvenil. Segundo elas, "Discute-se como no imaginário dos mesmos se delineia o debate. valorações e sentidos, o que se associa com percepções sobre o que é ou não apropriado à geração de referência: os jovens. Analisam-se, também, discriminações e preconceitos sofridos por jovens grávidas e mães solteiras no ambiente escolar" (p. 128). Discute-se, para tanto, as concepções sobre gravidez na adolescência na literatura, começando pela visão que a vê como um problema. Procura-se relativizar generalizações, frisando-se o cuidado com análises funcionalistas, dicotômicas e associações "empobrecedoras da complexidade compreensiva sobre o tema e seus múltiplos significados" (p. 135). Em seguida, as pesquisadoras dissertam sobre as representações a respeito do tema na escola, analisando o conhecimento dos professores, pais e alunos. São pesquisadas também as percepções desses atores sobre as possíveis causas de uma gravidez não planejada. Nos dados, questões de gênero chamam a atenção como, por exemplo, "a reprodução de uma ideologia pela qual cabe somente às mulheres a responsabilidade para com a relação entre sexualidade e fecundação" (p. 148). Outro exemplo é o fato de ser superior, em todas as capitais brasileiras, o percentual de mães que conversam sobre gravidez e regulação da concepção, reiterando a lógica de gênero pela qual caberia à mulher cuidar dos nexos entre sexualidade e gravidez. Outro aspecto analisado foi a percepção desses atores do ambiente escolar sobre as conseqüências de uma gravidez não planejada.

O quarto capítulo versa sobre a contracepção na juventude, e nele são analisados os níveis de conhecimento desses jovens a respeito dos métodos e formas de contracepção, "destacando como o gênero e o ciclo de vida da população jovem pode imprimir singularidades quanto a saberes e práticas" ( $p$. 171). São pesquisados também os motivos apresentados para o uso ou não da camisinha nas negociações sobre prevenção. As autoras colocam que "A negociação do uso do preservativo masculino esbarra em padrões sociais pautados em relações de gênero vulnerabilizando particularmente as mulheres, muitas vezes com sua cumplicidade, é quando a insegurança afetiva, noções de amor romântico e fidelidade podem contribuir para que estas abram a guarda em relação à administração de seu poder de fecundação e direito a se prevenir em relação a DST/AIDS - o que se demostra nas análises sobre motivos para o não uso da camisinha" (p. 171). Um fato interessante encontrado na pesquisa refere-se à indução à negligência quanto à prevenção, entre os rapazes, a partir de uma construção simbólica de masculinidade, na qual se consideram onipotentes. A confiança aparece como um tema comum em muitos discursos justificando o nãouso da camisinha, apesar de algumas exceções. Observa-se na pesquisa que a não-utilização do preservativo também está associada à decisão do parceiro, sendo comum a garota se submeter à vontade do garoto. As garotas declaram também que muitas vezes não pedem para os meninos usarem por motivos como ter vergonha, não quebrar o clima, entender que a iniciativa deva partir deles e não interferir na espontaneidade do ato. Por outro lado, outros jovens "comentam que o governo deveria incentivar mais o uso da camisinha, por meio de propaganda e comerciais, não somente no carnaval" (p. 201). Nesse capítulo mostram-se também posicionamentos dos pais e professores sobre a distribuição de preservativos na escola.

O quinto capítulo trata do aborto. Inicia-se com a apresentação de algumas estimativas sobre aborto e, em seguida, são analisadas percepções e informações que os atores em questão possuem sobre o tema. Entre os dados levantados, encontra-se que os jovens, e também os membros do corpo técnico-pedagógico, justificam o aborto em casos de estrupo ou, em segundo lugar, quando a mãe corre perigo. A terceira justificativa fica para os casos em que o bebê possa nascer com defeito/doença. Essa ordem também persistiu entre as justificativas dos pais, e percebe-se a influência do discurso religioso quanto à questão. Encontrou-se uma relativa heterogeneidade de posições sobre o aborto, sendo que os índices de favorabilidade apresentam-se maiores naquelas situações amparadas pela lei. A pesquisa analisou também o grau de conhecimento desses atores sobre o tema.

Na seqüência, no sexto capítulo, os temas pesquisados são violências, preconceitos e discriminações. As autoras alertam sobre a 
"naturalização de muitas dessas violências, como racismo, o sexismo e a homofobia, que podem não ser percebidos como algo negativo $e$ intencional" (p. 255), chamando a atenção para a gravidade dessa questão em ambiente escolar, onde deveria haver um combate à violência. Nesse capítulo, são apontados alguns tipos de violência sexual (assédio, estupro, incesto), seguindo a literatura e a percepção dos atores dessa pesquisa. Investigaram-se os comportamentos e motivos dos adultos e jovens para a não-denúncia. Também foram analisados as discriminações e os preconceitos, principalmente aqueles contra homossexuais nas escolas. Ainda no capítulo sexto, ocorre um pequeno descuido das autoras quanto ao uso do termo homossexualismo em vez de homossexualidade (p. 284). Este último é o termo mais utilizado atualmente, desde que a homossexualidade deixou de ser considerada doença pela OMS. Na seqüência desse capítulo, as autoras do livro chamam a atenção para o cuidado quanto ao uso da linguagem e discursos de alunos e professores na escola. Indicam a existência de problemas no "objetivo do projeto escolar, de formar mentalidades por parâmetros de igualdade"(p. 286).

Finalizando, as autoras concluem que não há uma orientação única sobre sexualidade entre os jovens. Notam-se variações regionais e diversidade de posturas por gênero, o que, segundo as pesquisadoras, "reforça a idéia de que há juventudes e não uma juventude e há de se conhecer tendências e sentidos diversificados dados por jovens" (p. 305) a esse tema. As marcas de gênero ficam evidentes não somente com relação às percepções e vivências e constituição de individualidades no feminino e no masculino, mas também quanto a diferenciais de situações vividas por esses jovens, como iniciação sexual e prevenção. Um outro aspecto interessante sobre gênero encontrado na pesquisa diz respeito ao valor do sexo para ambos os sexos. Foi observado que tanto os garotos quanto as garotas estão próximos na recusa da assertiva de que o sexo é mais importante para os homens do que para as mulheres e também na recusa de que os homens gostam de ficar e as mulheres de namorar. O livro termina com recomendações gerais e algumas específicas relacionadas à comunidade escolar. Entre as gerais estão investir em programas nacionais e regionais, documentar experiências inovadoras sobre educação sexual e constituir redes de intercâmbio, investir em pesquisas, apoiar redes de direitos humanos, fortalecer movimentos sociais, apoiar projetos com a intenção de construção de masculinidade avessa a estereótipos, entre outras. Quanto às específicas, investimentos em espaços para escuta e debate com os pais, formação de jovens multiplicadores, capacitação de professores, entre diversas outras recomendações.

Pode-se considerar Juventudes e sexualidade uma das obras mais completas sobre - tema e sobre a realidade brasileira, que, certamente, é uma referência para trabalhos relacionados à sexualidade e à juventude. O livro está bem organizado e escrito, apresentando resumos no final de cada capítulo sobre os dados mais importantes. Percebe-se uma boa organização dos relatos dos grupos focais, entrelaçados com a teoria e as percepções dos pesquisadores.

Adriano Beiras

Universidade Federal de Santa Catarina 